Article

\title{
An Empirical Algorithm for Wave Retrieval from Co-Polarization X-Band SAR Imagery
}

\author{
Weizeng Shao ${ }^{1} \mathbb{D}$, Jing Wang ${ }^{1}$, Xiaofeng $\mathrm{Li}^{1,3, *} \mathbb{D}$ and Jian Sun ${ }^{2}$ \\ 1 Marine Science and Technology College, Zhejiang Ocean University, Zhoushan 316000, China; \\ shaoweizeng@zjou.edu.cn (W.S.); momozjhn@163.com (J.W.) \\ 2 Physical Oceanography Laboratory, Ocean University of China, Qingdao 266100, China; \\ sunjian77@ouc.edu.cn \\ 3 Global Science and Technology, National Oceanic and Atmospheric Administration (NOAA)-National \\ Environmental Satellite, Data, and Information Service (NESDIS), College Park, MD 20740, USA \\ * Correspondence: xiaofeng.li@noaa.gov; Tel.: +1-301-683-3144
}

Academic Editors: Xiaofeng Yang, Ferdinando Nunziata and Alexis Mouche Received: 17 April 2017; Accepted: 6 July 2017; Published: 11 July 2017

\begin{abstract}
In this study, we proposed an empirical algorithm for significant wave height (SWH) retrieval from TerraSAR-X/TanDEM (TS-X/TD-X) X-band synthetic aperture radar (SAR) co-polarization (vertical-vertical (VV) and horizontal-horizontal $(\mathrm{HH})$ ) images. As the existing empirical algorithm at X-band, i.e., XWAVE, is applied for wave retrieval from $\mathrm{HH}$-polarization TS-X/TD-X image, polarization ratio (PR) has to be used for inverting wind speed, which is treated as an input in XWAVE. Wind speed encounters saturation in tropical cyclone. In our work, wind speed is replaced by normalized radar cross section (NRCS) to avoiding using SAR-derived wind speed, which does not work in high winds, and the empirical algorithm can be conveniently implemented without converting NRCS in HH-polarization to NRCS in VV-polarization by using X-band PR. A total of 120 TS-X/TD-X images, 60 in VV-polarization and 60 in HH-polarization, with homogenous wave patterns, and the coincide significant wave height data from European Centre for Medium-Range Weather Forecasts (ECMWF) reanalysis field at a $0.125^{\circ}$ grid were collected as a dataset for tuning the algorithm. The range of SWH is from 0 to $7 \mathrm{~m}$. We then applied the algorithm to $24 \mathrm{VV}$ and 21 $\mathrm{HH}$ additional SAR images to extract SWH at locations of 30 National Oceanic and Atmospheric Administration (NOAA) National Data Buoy Center (NDBC) buoys. It is found that the algorithm performs well with a SWH stander deviation (STD) of about $0.5 \mathrm{~m}$ for both VV and $\mathrm{HH}$ polarization TS-X/TD-X images. For large wave validation (SWH 6-7 m), we applied the empirical algorithm to a tropical cyclone Sandy TD-X image acquired in 2012, and obtained good result with a SWH STD of $0.3 \mathrm{~m}$. We concluded that the proposed empirical algorithm works for wave retrieval from TS-X/TD-X image in co-polarization without external sea surface wind information.
\end{abstract}

Keywords: SAR; significant wave height; co-polarization; TerraSAR-X/TanDEM-X

\section{Introduction}

It is well known that space-borne synthetic aperture radar (SAR) is an efficiently instrument for wind and wave observation in a large coverage with high spatial resolution at seas. Most satellite SAR operates at X-band (TerraSAR-X (TS-X), TanDEM-X (TD-X), and Cosmo-SkyMed), C-band (Radarsat-1/2, ERS-1/2, Envisat-ASAR, Sentinel-1A/-1B and Chinese Gaofen-3), and L-band (Japanese ALOS-1/ALOS-2). TS-X and its twin TD-X have $514 \mathrm{~km}$ orbit height above earth and a 100-min orbit period with fine spatial resolution of image up to $1 \mathrm{~m}$. TS-X and TD-X SAR are officially operated by Germen Aerospace Center (DLR). In the past few years, several algorithms for winds [1-5] and waves [6-9] retrieval from TS-X/TD-X image have been developed. Geophysical model function 
(GMF) XMOD2 [4] and polarization ratio XPR2 [5] are the latest achievements for wind retrieval from VV-polarization and HH-polarization TS-X/TD-X image, respectively. After employing SAR-derived wind speed, waves can be estimated from TS-X/TD-X image by using the theoretic-based algorithm "Parameterized First-guess Spectrum Method" (PFSM) [9] or the empirical algorithms [6,7]. Recently, empirical wave retrieval algorithm is adapted for coastal application [8], considering the ship and wave breaking etc. in offshore region.

Algorithm PFSM [10-12] was originally exploited for wave retrieval from C-band SAR, which is based on the wave mapping mechanism on SAR, including tilt modulation, hydrodynamic modulation [13] and velocity bunching [14]. PFSM is developed similar to the "Max-Planck Institute" algorithm (MPI) [15-17], "Semi Parametric Retrieval Algorithm" scheme (SPRA) [18] and "Partition Rescaling and Shift Algorithm" (PARSA) [19]. All these algorithms need a first-guess wave spectrum and the "true" wave spectrum is inverted through a set of iterations by minimizing a cost function [15]. Algorithm MPI and PARSA take the outputs from numeric wave model [20] as the first-guess spectrum, and both of these require a long computing time. Algorithm SPRA employs wind speed from scatterometer to produce the first-guess wind-sea spectrum by using empirical parametric wave function and information on swell is regarded as the difference between the retrieval results mapping spectrum and the original SAR spectrum. In other words, the error in the wind-sea retrieval process is delivered into the swell retrieval process in SPRA scheme. PFSM separates the non-linear wind-sea and the linear-mapping swell spectrum by calculating the separation threshold of the wave number. Moreover, it searches for the best parameters, e.g., dominate wave phase velocity and peak propagation direction, together with SAR-derived wind speed so as to produce the best fit first-guess wind-sea wave spectrum by using empirical parametric wave function, e.g., Jonswap [21]. The composite wave spectrum is obtained, after the different wave spectrum portions are inverted from corresponding SAR intensity spectrum portions. In addition, there are several unconstrained algorithms [22,23], which can also be applied for waves retrieval in a particular sea state, e.g., a long wave dominant regime, however, the retrieval result usually contains information on swell due to the portion produced by shorter waves in a SAR spectrum is missing in the inversion schemes. In fact, the basic scattering physics is independent on radar frequency and imaging polarization. In our previous study [9], it was already proven that algorithm PFSM can be applied to invert wave spectrum from TS-X/TD-X image and then wave parameters are derived from the inverted wave spectrum. Validation against the third-generation wave model WaveWatch-III outputs through $16 \mathrm{HH}$-polarization TS-X/TD-X images show a $0.43 \mathrm{~m}$ Root-Mean-Square Error (RMSE) of significant wave height (SWH).

Due to the complex nature of modulation transfer functions (MTF) in these theoretic-based algorithms, researchers also exploited the empirical algorithms such as CWAVEs (CWAVE_ERS [24] and CWAVE_ENV [25]) algorithms for C-band SAR and XWAVE [6-8] algorithms for X-band SAR. In parallel, a few researches recently have made effort to build empirical algorithms for retrieving SWH through azimuthal cutoff wavelength on SAR [26-29]. CWAVEs describe a relationship among wave and several other variables, e.g., wind speed, radar cross section and a set of orthonormal decompositions in a two-dimensional SAR spectrum derived from SAR intensity image. However, CWAVEs were designed to retrieve wave information from particular C-band SAR mode image, e.g., wave mode that has a fixed incidence angle around $23^{\circ}$. XWAVE inherits the idea behind CWAVEs, which is exploited through a number of TS-X/TD-X images at full incidence angle ranged from $20^{\circ}$ to $50^{\circ}$. In the development of XWAVE [6,7], the algorithm coefficients were primarily tuned using VV-polarization TS-X/TD-X data acquired over National Oceanic and Atmospheric Administration (NOAA) moored buoys in the open ocean. The SWH retrieval results show good agreement with the outputs from numerical wave model data provided by DWD. SAR-derived wind speed is necessary in algorithm XWAVE. XMOD2 [4] are tuned by using an amount of VV-polarization TS-X/TD-X images and collocated winds from DWD. However, no reliable wind retrieval above $20 \mathrm{~m} / \mathrm{s}$ is achieved from TS-X/TD-X image by using XMOD2 due to no available data at such wind speeds in the tuning process. Thus far, two existing algorithms, PFSM and XWAVE, have not been implemented under 
tropical cyclone conditions yet. This is because XMOD is tuned and validated through VV-polarization TS-X/TD-X images and the DWD with the wind speeds up to $25 \mathrm{~m} / \mathrm{s}$. Moreover, the signal saturation problem also exists for SAR in tropical cyclone [30,31].

Recently, a new empirical approach was reported in [32], by which it is possible to directly retrieve SWH in tropical cyclones from normalized radar cross section (NRCS) of C-band wide ScanSAR image, e.g., Envisat-ASAR and Radarsat-1/2. Interestingly, that empirical model can be conveniently applied similarly to the SAR wind retrieval methodology. Although the validation against outputs from the third-generation wave models, including WaveWatch-III and SWAN, has exhibited encouraging results, there are still some weaknesses existed in the model as mentioned by the authors.

In this study, we propose an empirical algorithm for SWH retrieval from X-band SAR through improving existing XWAVE model. In particular, this developed model can be directly applied for HH-polarization TS-X/TD-X image without converting NRCS in HH-polarization into NRCS in VV-polarization. The proposed algorithm avoids using SAR-derived wind speed, which is known having large retrieval errors in tropical cyclone. Data collected at high sea state (SWH $>5 \mathrm{~m})$ are also included in the tuning dataset and the algorithm performs well under tropical cyclone condition.

The paper is organized as follows. SAR images and collocated NOAA in situ buoys dataset are introduced in Section 2. In Section 3, methodology of the proposed empirical model for SWH retrieval is presented and the coefficients of the proposed empirical function are tuned by the dataset. The comparison of SWH retrieved from SAR imagery and those measured by buoys is shown in Section 4. A case study for wave retrieval using two TS-X/TD-X images acquired during in tropical cyclone Sandy in 2012 is also presented. Conclusions are summarized in Section 5.

\section{Data Description}

SAR data used in this study includes $60 \mathrm{VV}$-polarization and $60 \mathrm{HH}$-polarization SAR images acquired between 2008 and 2015. As examples, a HH-polarization TS-X image in StripMap mode acquired in Gulf of Alaska at 03:05 UTC on 3 November 2011 is shown in Figure 1a while another VV-polarization ScanSAR mode TD-X image acquired near Southeast Newfoundland Coast at 21:17 UTC on 4 October 2013 is shown in Figure 1b.
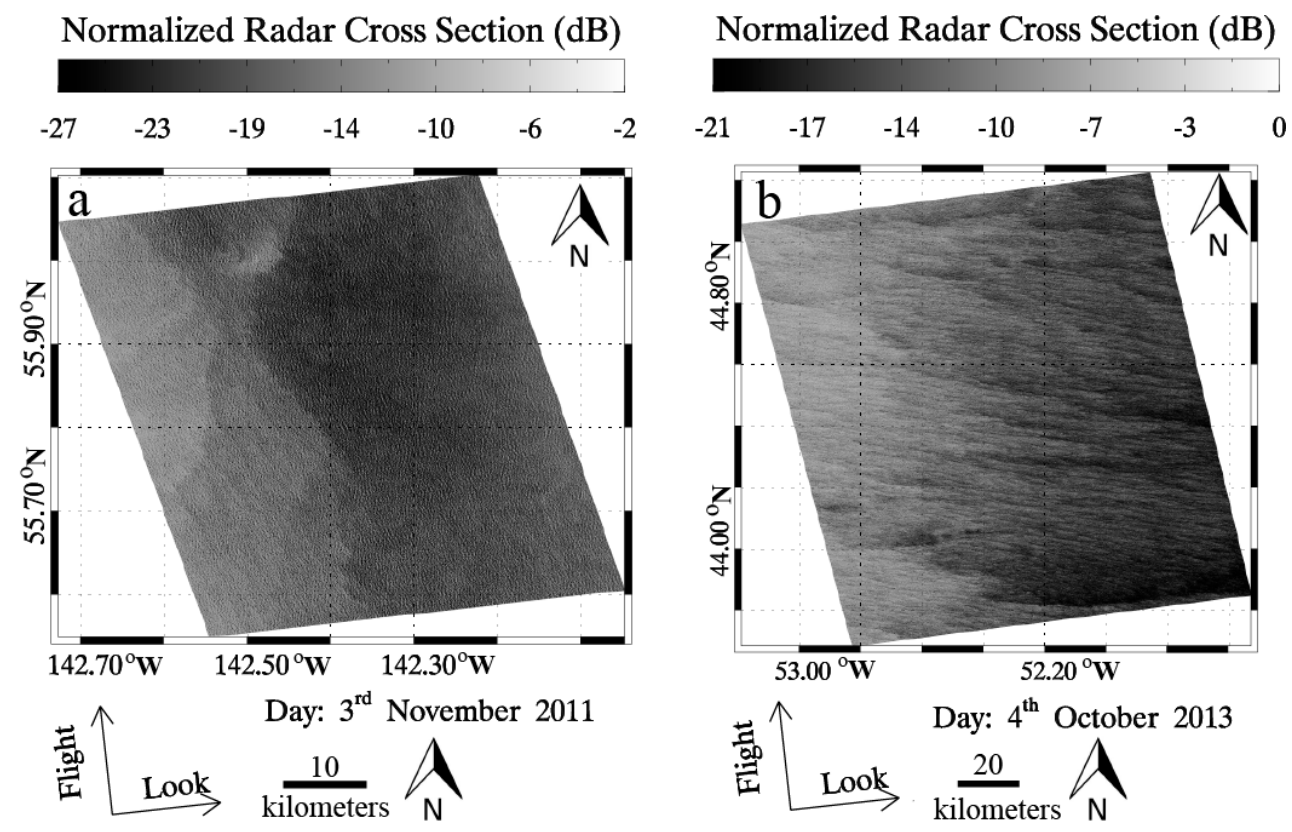

Figure 1. (a) A HH-polarization StripMap mode TerraSAR(TS-X) image acquired in Gulf of Alaska at 03:05 UTC on 3 November 2011; and (b) a VV-polarization ScanSAR mode TanDEM-X (TD-X) image acquired to the Southeast of Newfoundland at 21:17 UTC on 4 October 2013. 
In this study, the European Centre for Medium-Range Weather Forecasts (ECMWF) global atmospheric-marine reanalyzed data is matched up against the SAR measurements. Here, we used ECMWF reanalysis SWH data at a $0.125^{\circ}$ grid (approximate $12.5 \mathrm{~km}$ ) at an interval of six hours. To perform the matchup, every TS-X/TD-X imagery was divided into sub-scenes with a spatial coverage of $1.5 \times 1.5 \mathrm{~km}$ for StripMap mode and $4 \times 4 \mathrm{~km}$ for ScanSAR mode images in azimuth and range direction, respectively. Then, ECMWF SWH data in every sub-scene were calculated by both bilinear interpolation in space and time. To eliminate inhomogeneous sub-scenes, we compute the image variance and only keep those with values smaller than 1.05 [26]. Moreover, the SAR spectrum is smoothed to reduce the distortions of other marine phenomena. Figure $2 a, b$ shows the ECMWF SWH data that correspond to the two images shown in Figure 1a,b, respectively.
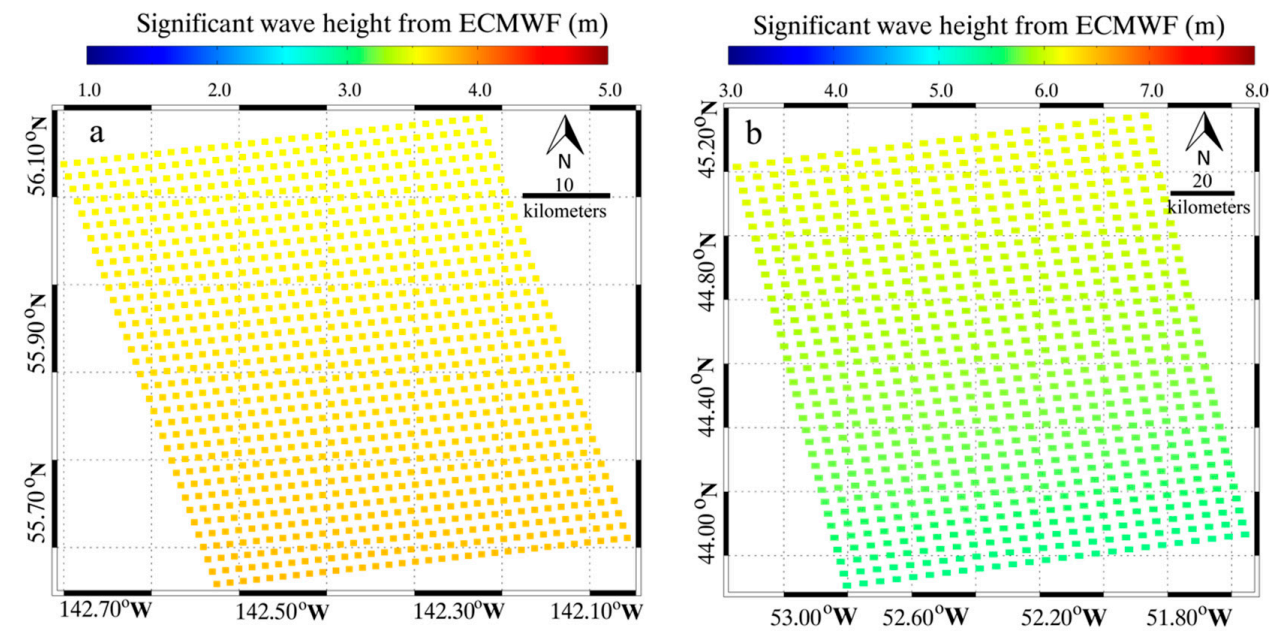

Figure 2. (a) Space and time interpolated European Centre for Medium-Range Weather Forecasts (ECMWF) SWH data corresponding to the SAR image in Figure 1a; and (b) same as (a) but for the SAR image in Figure 1b.

In total, our dataset consists of more than one thousand SAR-derived and ECMWF reanalysis SWH matchup points for algorithm tuning. Histograms of SWH matchups are shown in Figure 3, in which the SWH ranges from 0 to $7 \mathrm{~m}$ at interval of $0.3 \mathrm{~m}$.
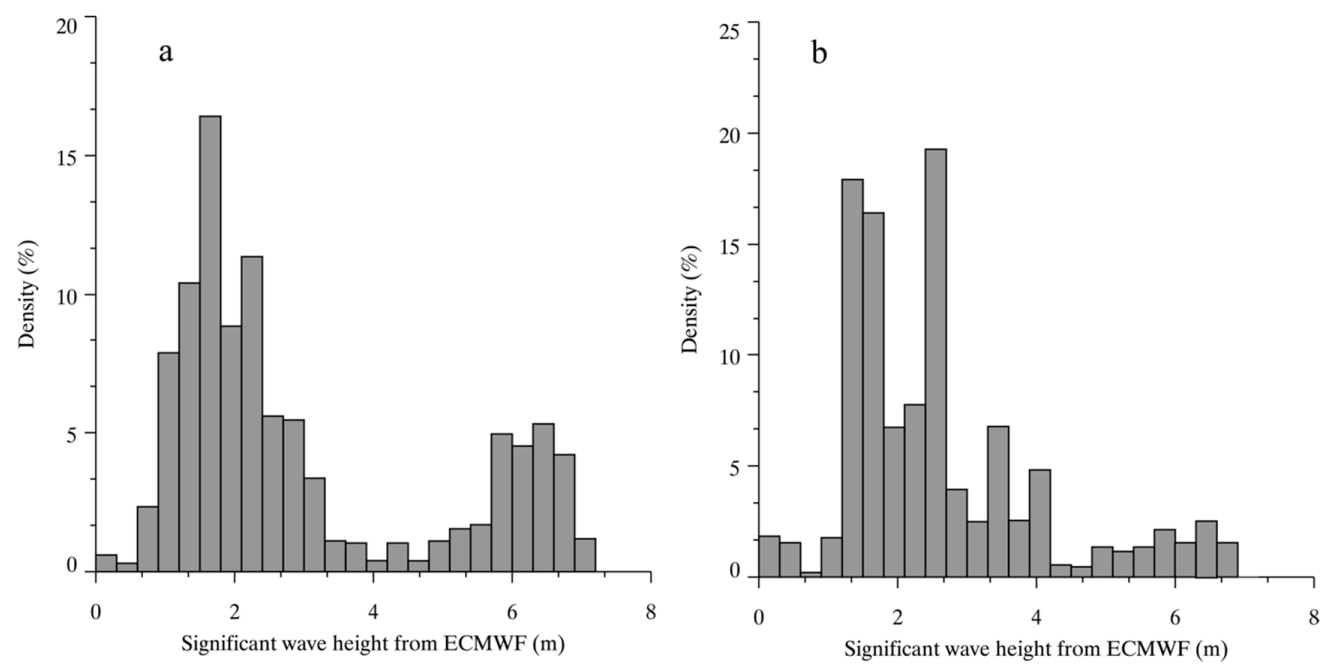

Figure 3. Histograms of SWH matchups at interval of $0.3 \mathrm{~m}$. SWH ranges from 0 to $7 \mathrm{~m}$ : (a) VV-polarization; and (b) HH-polarization. 


\section{Development of Empirical Algorithm for Wave Retrieval at X-Band}

\subsection{Existing X-Band SAR Wind and Wave Algorithms}

The wind retrieval from SAR is a matured technology. The initial X-band GMF, XMOD1, simply related VV-polarization X-band radar normalized radar cross section (NRCS) from TS-X/TD-X images to wind speed in a pre-launch study [1]. Then, similar to the development of C-band GMF CMOD5 [33] that was derived from ERS-1 SAR images and ECMWF reanalysis wind data, XMOD2 has been exploited in [4] by using collocated VV-polarization TS-X/TD-X images and National Data Buoy Center (NDBC) buoy measurements and it was found that a $1.44 \mathrm{~m} / \mathrm{s}$ RMSE of wind speed was achieved against NOAA in situ buoys. Besides, another X-band GMF, called SIRX-MOD, was proposed in [3] by retuning the coefficients in the C-band GMF CMOD-IFR2 [34] with the VV-polarization Spaceborne Imaging Radar (SIR) X-band SAR NRCS data and ECMWF reanalysis wind data. XMOD2 and SIRX-MOD take the general form of:

$$
\sigma_{0}=\mathrm{B}_{0}\left(1+\mathrm{B}_{1} \cos \phi+\mathrm{B}_{2} \cos 2 \phi\right)
$$

where $\sigma_{0}$ is the NRCS in linear unit, and $\phi$ represents the angle between the radar look direction and the wind direction. The coefficients $\mathrm{B}_{0}, \mathrm{~B}_{1}$ and $\mathrm{B}_{2}$ are functions of the radar incidence angle $\theta$ and sea surface wind speed $U_{10}$ at $10 \mathrm{~m}$ height above sea surface. Figure 4 shows the XMOD2 and SIRX-MOD curves at $\theta$ of $30^{\circ}$ and $\phi$ of $45^{\circ}$, showing X-band NRCS is linearly related to wind speed. This behavior is consistent with the observations of microwave backscattering signatures of the ocean at X-band during the experiment using an airborne microwave scatterometer-radiometer system [35]. As for wind retrieval from $\mathrm{HH}$-polarization TS-X/TD-X image, polarization ratio (PR) model is used to convert NRCS values from VV to HH. X-band PR (XPR) models for TS-X/TD-X are given for [2,5]. It was reported in [5] that the comparison of wind speed by using the combination method, that is XMOD2 together with XPR2, shows a RMSE of $1.79 \mathrm{~m} / \mathrm{s}$ against winds measured by NOAA buoys. However, these algorithms are only valid for wind speeds up to $25 \mathrm{~m} / \mathrm{s}$, because they are exploited through low-to-moderate wind speeds.

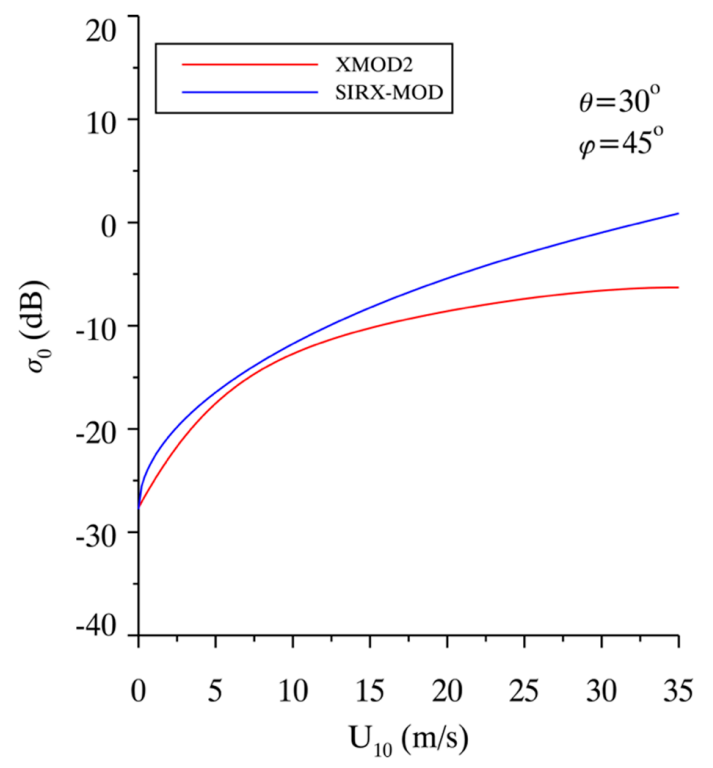

Figure 4. The simulation of XMOD2 and SIRX-MOD at $\theta$ of $30^{\circ}$ and $\phi$ of $45^{\circ}$.

Based on SAR-derived wind speed, two wave retrieval algorithms, a theoretic-based PFSM [9] algorithm and an empirical XWAVE model [6], have been developed for TS-X/TD-X image. XWAVE takes the form of: 


$$
\mathrm{H}_{\mathrm{S}}=\mathrm{A}_{1} \sqrt{\mathrm{E}_{\mathrm{s}} \tan \theta}+\mathrm{A}_{2} \mathrm{U}_{10}+\mathrm{A}_{3}+\mathrm{A}_{4} \cos \phi
$$

where $H_{s}$ is the SWH, $\theta$ is the radar incidence angle, $U_{10}$ is the wind speed at $10 \mathrm{~m}$ above sea surface, $\phi$ is the wave peak direction relative to azimuth direction ranged from 0 to $90^{\circ}$, $\mathrm{E}_{\mathrm{S}}\left(=\int_{0}^{2 \pi} \int_{\mathrm{k}_{\min }}^{\mathrm{k}_{\max }} \overline{\mathrm{S}}(\mathrm{k}, \theta) \mathrm{dkd} \theta\right)$ is the integrated value of the normalized SAR intensity spectrum $\bar{S}(k, \theta)$ in wavelength domain $L_{\min }\left(=2 \pi / k_{\min }\right)$ of 30 to $L_{\max }\left(=2 \pi / k_{\max }\right)$ of $600 \mathrm{~m}$, and the coefficients $\mathrm{A}_{1}$ to $\mathrm{A}_{4}$ are the constants tuned by VV-polarization TS-X/TD-X images together with SWH from DWD and NOAA buoys in [6,7]. XWAVE is conveniently applied for waves retrieval from TS-X/TD-X images without transferring SAR intensity spectrum into wave spectrum. Although SAR-derived wind speed from VV-polarization and HH-polarization TS-X/TD-X image has known accuracy at within $2 \mathrm{~m} / \mathrm{s}$ RMSE of wind speed [4,5], XWAVE is restrictedly used during operational application, due to prior wind direction is necessary in the process of wind retrieval by using XMODs.

\subsection{Empirical Algorithm for Wave Retrieval in Both VV-and HH-Polarization}

X-band GMF XMOD2 and PR model XPR2 are valid for winds up to $25 \mathrm{~m} / \mathrm{s}$ due to no available higher winds in the tuning dataset. In this study, we develop an empirical wave retrieval algorithm by replacing wind speed with NRCS in Equation (2). The purpose of this kind of development is that the empirical algorithm can be conveniently implemented without calculating the sea surface wind speed. The proposed empirical model takes the form:

$$
\mathrm{H}_{\mathrm{s}}=\mathrm{C}_{1} \sqrt{\mathrm{E}_{\mathrm{s}} \tan \theta}+\mathrm{C}_{2} \sigma^{0}+\mathrm{C}_{3}+\mathrm{C}_{4} \cos \alpha
$$

where, $\alpha$ represents the peak direction relative to azimuth direction in a SAR spectrum instead of wave peak direction $\phi$ in Equation (2) for convenient application. The collocated dataset, including ECMWF SWH data and the three other variables derived from SAR intensity spectrum, is used for tuning the coefficients $\mathrm{C}_{1}$ to $\mathrm{C}_{4}$ in VV-polarization and $\mathrm{HH}$-polarization. The values of matrix $\mathrm{C}$ in Equation (3) for VV-polarization and HH-polarization are shown in Tables 1 and 2, respectively.

The statistical analysis between the ECMWF reanalysis $\mathrm{SWH}$ and the simulated SWH by using proposed algorithm is exhibited in Figure 5 for $10^{\circ}$ of incidence angle bins between $20^{\circ}$ and $50^{\circ}$ and $1 \mathrm{~m}$ of SWH bins ranged from 0 to $7 \mathrm{~m}$. The result shows the correlation is about 0.8 . Under this circumstance, it is indicated that the proposed algorithm is suitable for $\mathrm{H}_{\mathrm{s}}$ retrieval from VV and $\mathrm{HH}$ polarization TS-/TD-X image. However, it is necessary to figure out if the proposed algorithm relies on good-quality power spectra of SAR image.

Table 1. Tuned coefficients in Equation (3) for VV-polarization.

\begin{tabular}{ll}
\hline $\mathrm{C}_{1}$ & 2.90 \\
\hline $\mathrm{C}_{2}$ & 3.31 \\
\hline $\mathrm{C}_{3}$ & 0.47 \\
\hline $\mathrm{C}_{4}$ & 0.58 \\
\hline
\end{tabular}

Table 2. Tuned coefficients in Equation (3) for $\mathrm{HH}$-polarization.

\begin{tabular}{ll}
\hline $\mathrm{C}_{1}$ & 2.11 \\
\hline $\mathrm{C}_{2}$ & 2.21 \\
\hline $\mathrm{C}_{3}$ & 0.91 \\
\hline $\mathrm{C}_{4}$ & 0.64 \\
\hline
\end{tabular}




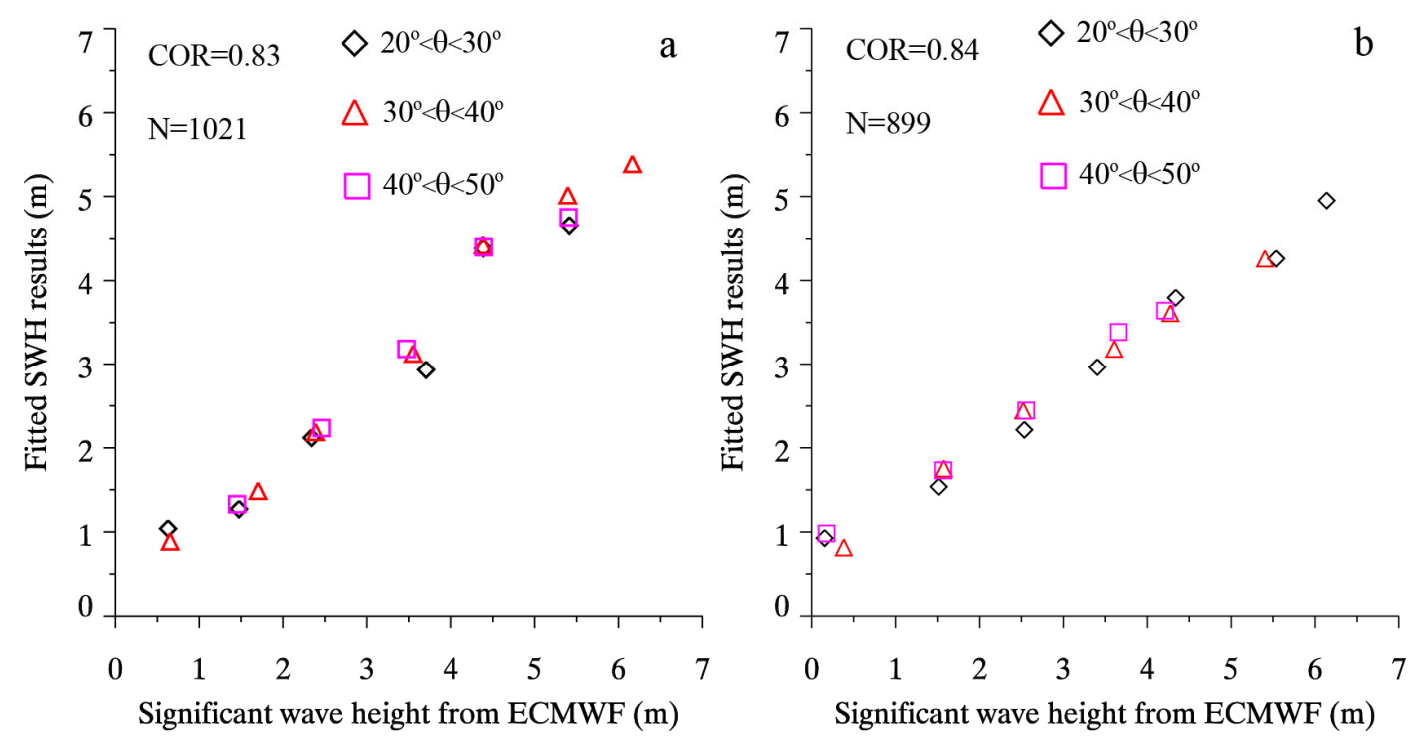

Figure 5. ECMWF SWH data versus fitted SWH results, for $10^{\circ}$ incidence angle bins between $20^{\circ}$ and $50^{\circ}$ and $1 \mathrm{~m} / \mathrm{s} \mathrm{SWH}$ bins ranging from 0 to $7 \mathrm{~m} / \mathrm{s}$ : (a) VV-polarization; and (b) HH-polarization.

\section{Validation}

\subsection{Validation Against Buoys}

As a case study, the image of HH-polarization TS-X image in StripMap mode acquired at 16:19 UTC on 1 February 2012 at 13:59 UTC is shown in Figure 6, which covers the NOAA in situ buoy (ID: 46047). A sub-scene of $2048 \times 2048$ pixels with a $1.25 \times 1.25$ pixel size has been extracted from TS-X image, which covers the location of NDBC buoy. The sub-scene is normalized and then the sub-scene is divided into $2 \times 2$ small scenes. The corresponding four two-dimensional SAR spectra are calculated by using the two-dimensional Fast Fourier Transform (FFT-2) method. The smooth two-dimensional spectrum, which is obtained by averaging the four two-dimensional SAR spectra, is used here.

The image of sub-scene and the corresponding two-dimensional wave spectrum in term of length $\lambda$, is shown in Figure 7a,b. The SAR-derived SWH in area A centered at the buoy location is $2.01 \mathrm{~m}$ and the buoy-measured SWH is $2.48 \mathrm{~m}$. As for this case study, the difference between retrieve SWH and observed SWH is $0.47 \mathrm{~m}$.

We apply the X-band wave retrieval algorithm to extract SWH values from $24 \mathrm{VV}$-polarization and $21 \mathrm{HH}$-polarization TS-X/TD-X images. In these SAR images, they also contain 30 NOAA buoy locations. The information of SAR images and corresponding NDBC buoys is shown in Appendix A. The SAR-derived wave information is matched up against co-located NOAA buoy measurements.

As shown in Figure 8, the RMSE of SWH is $0.5 \mathrm{~m}$ with a $27 \%$ scatter index (SI) for VV-polarization images and the RMSE of SWH is $0.52 \mathrm{~m}$ with a $36 \%$ SI for HH-polarization images. The stander deviation (STD) of SWH is $0.5 \mathrm{~m}$ between retrieval results from co-polarization TS-X/TD-X images and buoy measurements. We found that SAR-derived SWH by using the proposed algorithm has a similar accuracy to the analysis results by using the existing wave retrieval algorithms, which has a SWH STD of around $0.5 \mathrm{~m}$ as validated against observations from moored buoys or altimeters [18,24,25]. Again, it should be noted that the proposed empirical XWAVE model can be directly applicable without knowing the information on wind speed and PR model is not required as it is applied for HH-polarization TS-X/TD-X image. 


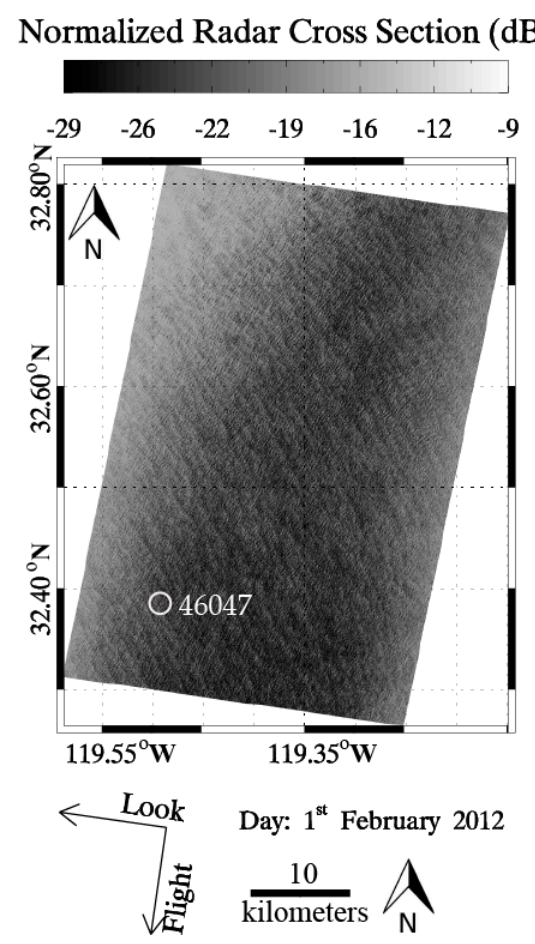

Figure 6. The image of HH-polarization TS-X image in StripMap mode acquired at 16:19 UTC on 1 February 2012, covering the NOAA in situ buoy (ID: 46047).
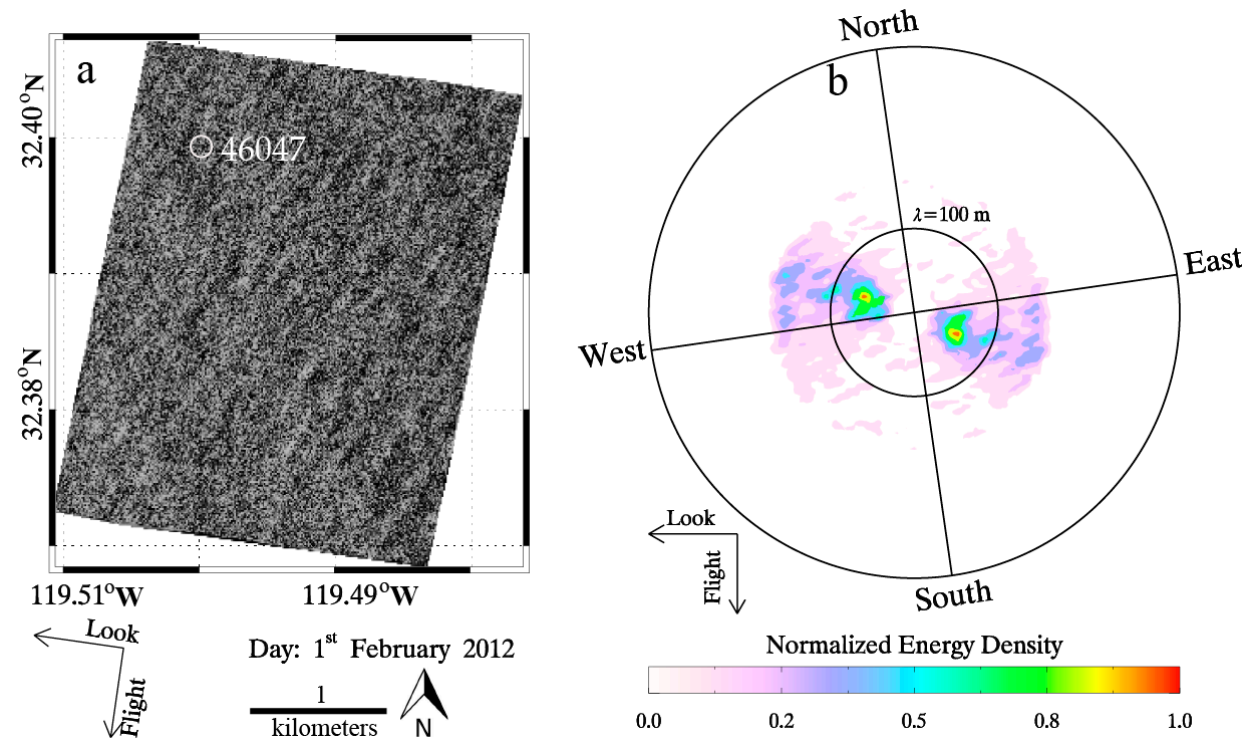

Figure 7. (a) Intensity image of sub-scene covering the NOAA in situ buoy (ID: 46047); and (b) the two-dimensional SAR spectrum in term of length $\lambda$ corresponding to the sub-scene. 

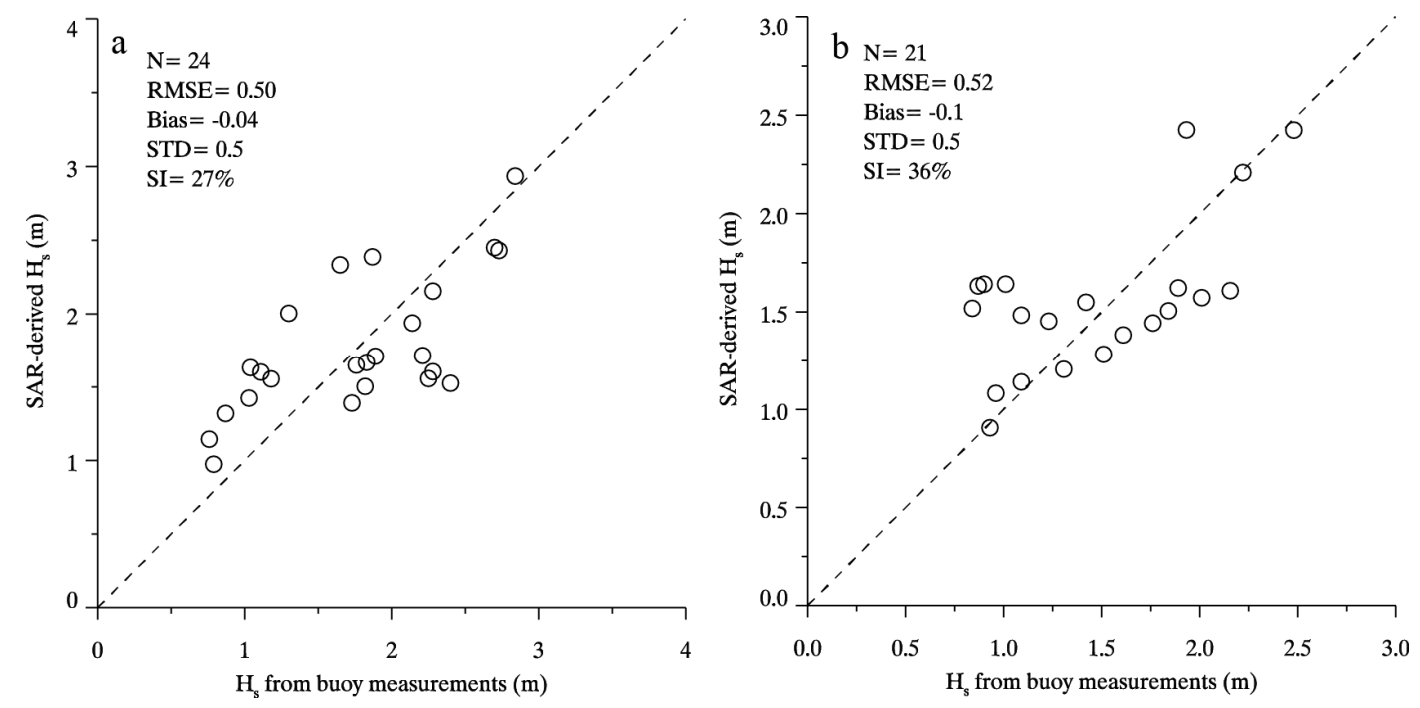

Figure 8. SWH retrieval results from TS-X/TD-X images are compared with buoy measurements: (a) VV-polarization images; and (b) HH-polarization images.

\subsection{Application in Trpocial Cyclone}

Further, we also validate the algorithm for one TD-X image taken during tropical cyclone Sandy in 2012. SAR has the capacity of all-weather field monitoring, especially in tropical cyclones. Through several tropical cyclones captured by SAR, some achievements have been exhibited in [36-40], e.g., morphology of cyclones [36-38], hurricane-generated ocean swell refraction [39] and a new method of high wind speed retrieval [40]. The comparison of wind retrieval using VV-polarization C-band SAR backscattering in hurricanes was reported in [41]. The results show RMSE of wind speed is 6.2-6.5 m/s against measurements from Stepped Frequency Microwave Radiometer (SFMR), due to winds encounter saturation problem as winds growing under tropical cyclone condition [30,31]. Therefore, SAR-derived wind speeds have a large deviation with reality in tropical cyclones. To eliminate this source of errors, we replaced the wind speed with the NRCS in the existing XWAVE formula in this study. The advantage of this development is that the application of proposed algorithm avoids using SAR-derived wind speed, which is not working at high winds.

The multi-look ground range detected (MGD) VV-polarization TD-X SAR image in ScanSAR mode acquired over tropical cyclone Sandy at 22:49 UTC on 28 October 2012 is shown in Figure 9. The TD-X image has an $8.25 \times 8.25 \mathrm{~m}$ pixel size in both azimuth and range directions and then it was divided into sub-scenes of $512 \times 512$ pixels, which correspond to a spatial coverage of about $4 \times 4 \mathrm{~km}$. The sub-scenes were processed to retrieve SWH by using the developed algorithm. However, about $15 \%$ of sub-scenes are contaminated by the rain. These data were excluded in this study.

There are no NOAA buoys within the TD-X image's coverage. Therefore, we only perform the comparison against ECMWF results. The commonly used WaveWatch-III model output has a spatial resolution of $0.5^{\circ}$ grid, which is too coarser than the ECMWF model results. Figure 10 shows that the SAR-derived SWH from the TD-X image in tropical cyclone Sandy and ECMWF reanalysis SWH at a $0.125^{\circ}$ grid, in which the black rectangle represents the coverage of TD-X image. In particular, the time between the TD-X imaging time and ECMWF reanalysis SWH data is comparatively close, i.e. within $2 \mathrm{~h}$. In general, the SAR-derived SWH is agreeable to the ECMWF reanalysis SWH data. Then the SAR-derived SWH points matched up closest to ECMWF grid points are selected. Figure 11 shows a $0.35 \mathrm{~m}$ RMSE of the SWH comparison. The unique ECMWF reanalysis SWH data were used for tuning and validating the proposed empirical algorithm, causing a better $0.3 \mathrm{~m} \mathrm{STD}$ than a $0.5 \mathrm{~m}$ STD of SWH. Although ECMWF reanalysis SWH data deviate from reality, the statistical analysis of the 
case study still reveals the proposed empirical wave retrieval algorithm has a creditable performance under tropical cyclone condition.

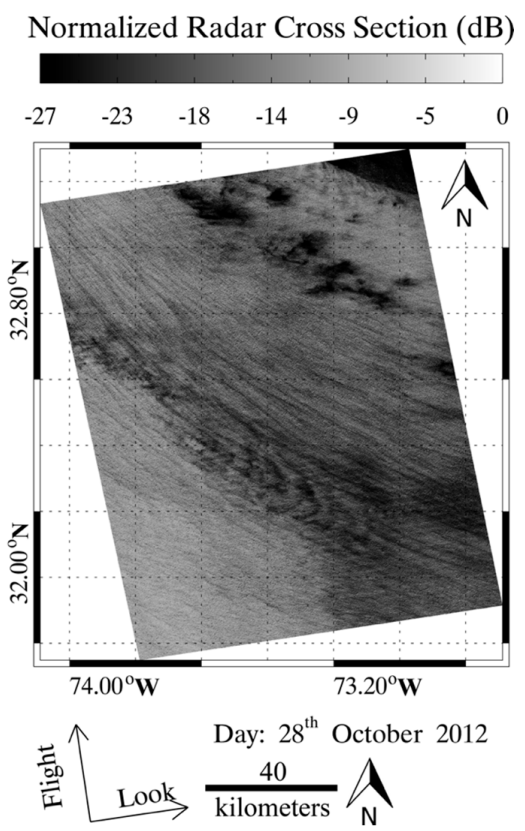

Figure 9. The image of VV-polarization TD-X SAR image in ScanSAR mode acquired over tropical cyclone Sandy at 22:49 UTC on 28 October 2012.

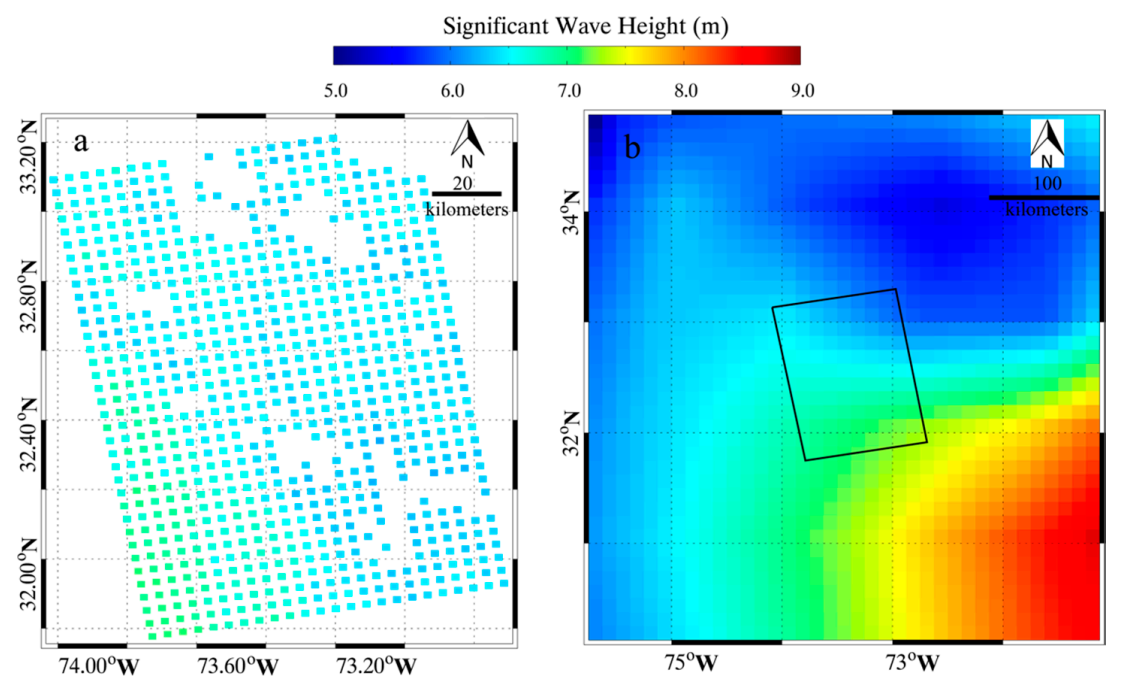

Figure 10. (a) The SAR-derived SWH from TD-X image over tropical cyclone Sandy at 22:49 UTC on 28 October 2012. (b) ECMWF reanalysis SWH data at 00:00 UTC on 29 October 2012 at a $0.125^{\circ}$ gird, in which the rectangle represents the coverage of TD-X image. 


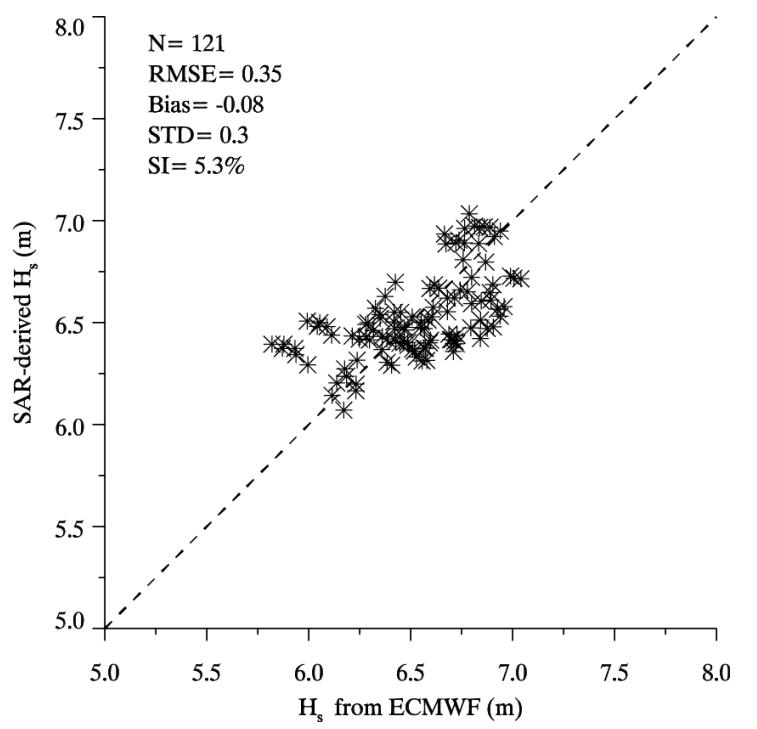

Figure 11. The comparison between SAR-derived SWH by using the proposed empirical algorithm and ECMWF reanalysis SWH data.

\section{Conclusions}

XWAVE's design was aimed to wave retrieval from VV-polarization TS-X/TD-X image, which relies on SAR-derived wind speeds. Although several algorithms have been recently exploited for wind retrieval from co-polarization TS-X/TD-X image, such as GMF SIRX-MOD [3], GMF XMOD2 [4] and polarization ratio XPRs [2,5], these algorithms are only valid for wind speeds up to $25 \mathrm{~m} / \mathrm{s}$. When XWAVE is applied for wave retrieval from HH-polarization TS-X/TD-X image, XPR has to be used for converting NRCS in HH-polarization to NRCS in VV-polarization to retrieve wind speed. It is well known that SAR NRCS has a strong relation with wind speed. This is true for C-band [33] and X-band SAR [35]. In this study, we proposed an empirical algorithm by replacing NRCS instead of wind speed in the existing XWAVE model. Therefore, this development benefits the operation of waves retrieval from $X$-band SAR due to its application without using SAR-derived wind speeds.

In our work, 60 TS-X/TD-X images in VV-polarization and 60 TS-X/TD-X images in $\mathrm{HH}$-polarization were collected over whole seas. All these images were divided into numbers of sub-scenes, which were collocated with ECMWF SWH data at a $0.125^{\circ}$ grid. We have more than one thousand matchups to tune the proposed empirical algorithm. An additional 24 images in VV-polarization and 21 images in HH-polarization were implemented using the proposed empirical algorithm and the retrieval results were validated against the observations from 30 NOAA in situ buoys, showing a 0.5 STD of SWH. XWAVE needs convert NRCS in HH-polarization to NRCS in VV-polarization by using XPRs and it relies on SAR-derived wind speed which has a deviation with reality. The proposed algorithm directly works for both VV-polarization and HH-polarization without using XPRs. The correlation between the ECMWF reanalysis SWH and the simulated SWH is about 0.8. Therefore, we think the proposed algorithm is suitable for wave retrieval from co-polarization TS-X/TD-X image.

The validation of wind speed retrieved from TS-X/TD-X image using XMOD has not been investigated yet under tropical cyclone condition. Therefore, the advantage of the proposed empirical algorithm is that wind speed is no longer needed for wave retrieval in tropical cyclone. One VV-polarization TD-X image in tropical cyclone Sandy in 2012 was used to confirm the applicability of the proposed algorithm. Because no moored buoys were available in the TS-X coverage, and wave data from WaveWatch-III model have a $0.5^{\circ}$ grid, which is too coarse for validation, we use ECMWF reanalysis SWH to preliminary evaluate the performance of the proposed algorithm. The comparison between SAR-derived SWH and ECMWF reanalysis SWH data shows a $0.3 \mathrm{~m}$ STD of SWH meaning 
the proposed empirical algorithm also works under tropical cyclone condition. A new method of wind retrieval in tropical cyclone was proposed in [40], in which wind speeds up to $65.4 \mathrm{~m} / \mathrm{s}$ were retrieved from the information on waves using the fetch-limited wind wave growth function. The validation shows a good agreement with hurricane hunter measurements and there is no indication of saturation problem in the wind retrieval. In the near future, we plan to validate the proposed algorithm through more X-band SAR images in tropical cyclones, covering the moored buoys. Then winds can be retrieved from X-band SAR image through SAR-derived SWH.

Acknowledgments: TS-X/TD-X images were acquired via the science AOs of OCE3150 and OCE3356 provided from German Aerospace Center (DLR). Buoy data are downloaded via http:/ / www.ndbc.noaa.gov/. ECMWF reanalysis wave data were openly accessed via http:/ /www.ecmwf.int. The research is partly supported by the National Key Research and Development Program of China under Grant No. 2017YFA0604901, National Natural Science Foundation of China under Grant No. 41376010 and Foundation of Zhejiang Ocean University (2015). The views, opinions, and findings contained in this report are those of the authors and should not be construed as an official NOAA or U.S. Government position, policy or decision.

Author Contributions: Weizeng Shao, Jian Sun and Xiaofeng Li came up the original idea and designed the experiments. Weizeng Shao and Jing Wang collected and analyzed the data. All authors contributed to the writing and revising of the manuscript.

Conflicts of Interest: The authors declare no conflict of interest.

\section{Appendix A}

Table A1. The information of TS-X/TD-X images and corresponding NDBC buoys used in our study.

\begin{tabular}{|c|c|c|c|c|c|}
\hline $\begin{array}{l}\text { Buoy } \\
\text { ID }\end{array}$ & $\begin{array}{l}\text { TS-X/TD-X Acquisition } \\
\text { Time (YYYY-MM-DD) }\end{array}$ & $\begin{array}{l}\text { Imaging } \\
\text { Mode }\end{array}$ & $\begin{array}{l}\text { Buoy } \\
\text { ID }\end{array}$ & $\begin{array}{l}\text { TS-X/TD-X Acquisition } \\
\text { Time (YYYY-MM-DD) }\end{array}$ & $\begin{array}{l}\text { Imaging } \\
\text { Mode }\end{array}$ \\
\hline 46013 & 2008-02-22 02:08 & StripMap & 46011 & 2011-03-13 14:07 & ScanSAR \\
\hline 46026 & 2008-03-02 14:15 & StripMap & 46054 & 2011-03-15 01:59 & StripMap \\
\hline 46029 & 2009-03-19 02:02 & ScanSAR & 46050 & 2011-10-23 14:30 & StripMap \\
\hline 41048 & $2009-05-13$ 22:31 & StripMap & 41047 & $2011-10-25$ 10:51 & StripMap \\
\hline 46025 & 2009-06-10 01:50 & ScanSAR & 46050 & 2011-10-26 02:11 & StripMap \\
\hline 46221 & 2009-07-19 01:42 & ScanSAR & 46229 & $2011-10-26$ 02:10 & StripMap \\
\hline 46221 & 2009-09-12 01:42 & ScanSAR & 46015 & 2011-11-06 02:10 & StripMap \\
\hline 46028 & 2010-04-08 01:59 & ScanSAR & 41047 & 2011-11-06 22:39 & StripMap \\
\hline 46015 & 2010-06-13 02:01 & ScanSAR & 46015 & 2011-11-28 02:10 & StripMap \\
\hline 46013 & 2010-07-05 02:00 & ScanSAR & 46050 & 2011-12-04 02:02 & StripMap \\
\hline 46029 & 2010-07-05 02:02 & StripMap & 46015 & 2011-12-04 02:01 & StripMap \\
\hline 42036 & 2010-07-06 11:42 & StripMap & 41043 & $2012-01-23$ 22:20 & StripMap \\
\hline 46028 & 2010-07-16 01:59 & StripMap & 46047 & 2012-02-01 13:59 & StripMap \\
\hline 46011 & 2010-11-12 14:07 & StripMap & 51000 & 2012-02-26 16:19 & StripMap \\
\hline 46022 & 2010-11-16 14:31 & StripMap & 46222 & 2012-03-27 13:59 & StripMap \\
\hline 46011 & 2010-11-17 14:15 & StripMap & 46011 & 2012-05-23 01:51 & StripMap \\
\hline 44008 & 2010-11-20 22:25 & StripMap & 46025 & 2013-02-03 14:07 & ScanSAR \\
\hline 51000 & 2010-12-13 16:19 & ScanSAR & 41048 & 2013-02-05 22:32 & StripMap \\
\hline 46053 & $2010-12-15$ 14:07 & ScanSAR & 41002 & 2013-04-04 11:07 & ScanSAR \\
\hline 46012 & 2010-12-17 02:00 & ScanSAR & 46011 & $2013-06-28$ 01:59 & ScanSAR \\
\hline 51000 & 2010-12-20 04:14 & ScanSAR & 46053 & 2013-09-22 14:07 & ScanSAR \\
\hline 51000 & 2010-12-24 16:19 & ScanSAR & 52200 & 2015-04-13 08:22 & StripMap \\
\hline 46050 & 2011-03-04 02:02 & ScanSAR & & & \\
\hline
\end{tabular}

\section{References}

1. Ren, Y.Z.; He, M.X.; Lehner, S. An algorithm for the retrieval of sea surface wind fields using X-band TerraSAR-X data. Int. J. Remote Sens. 2012, 33, 7310-7336. [CrossRef]

2. Shao, W.Z.; Li, X.M.; Lehner, S.; Guan, C.L. Development of polarization ratio model for sea surface wind field retrieval from TerraSAR-X HH polarization data. Int. J. Remote Sens. 2014, 35, 4046-4063. [CrossRef] 
3. Ren, Y.Z.; Li, X.M.; Zhou, G. Sea surface wind retrievals from SIR-C/X-SAR data: a revisit. Remote Sens. 2015, 7, 3548-3564. [CrossRef]

4. Li, X.M.; Lehner, S. Algorithm for sea surface wind retrieval from TerraSAR-X and TanDEM-X Data. IEEE Trans. Geosci. Remote Sens. 2014, 52, 2928-2939. [CrossRef]

5. Shao, W.Z.; Zhang, Z.; Li, X.M.; Wang, W.L. Sea surface wind speed retrieval from TerraSAR-X HH-polarization data using an improved polarization ratio model. IEEE J. Sel. Top. Appl. Earth Obs. Remote Sens. 2016, 9, 4991-4997. [CrossRef]

6. Bruck, M.; Lehner, S. Coastal wave field extraction using TerraSAR-X data. J. Appl. Remote Sens. 2013, 107, 333. [CrossRef]

7. Bruck, M. Sea state measurements using the XWAVE algorithm. Int. J. Remote Sens. 2015, 36, 3890-3912. [CrossRef]

8. Pleskachevsky, A.L.; Rosenthal, W.; Lehner, S. Meteo-Marine parameters for highly variable environment in coastal regions from satellite radar images. ISPRS J. Photogramm. 2016, 119, 464-484. [CrossRef]

9. Shao, W.Z.; Li, X.F.; Sun, J. Ocean wave parameters retrieval from TerraSAR-X images validated against buoy measurements and model results. Remote Sens. 2015, 7, 12815-12828. [CrossRef]

10. Sun, J.; Guan, C.L. Parameterized first-guess spectrum method for retrieving directional spectrum of swell-dominated waves and huge waves from SAR images. Chin. J. Oceanol. Limn. 2006, 24, 12-20.

11. Sun, J.; Kawamura, H. Retrieval of surface wave parameters from SAR images and their validation in the coastal seas around Japan. J. Oceanogr. 2009, 65, 567-577. [CrossRef]

12. Lin, B.; Shao, W.Z.; Li, X.F.; Li, H.; Du, X.Q.; Ji, Q.Y.; Cai, L.N. Development and validation of an ocean wave retrieval algorithm for VV-polarization Sentinel-1 SAR data. Acta Oceanol. Sin. 2017, 36, 95-101. [CrossRef]

13. Alpers, W.; Ross, D.B.; Rufenach, C.L. On the detectability of ocean surface waves by real and synthetic radar. J. Geophys. Res. 1981, 86, 10529-10546. [CrossRef]

14. Alpers, W.; Bruning, C. On the relative importance of motion-related contributions to SAR imaging mechanism of ocean surface waves. IEEE Trans. Geosci. Remote Sens. 1986, 24, 873-885. [CrossRef]

15. Hasselmann, K.; Hasselmann, S. On the nonlinear mapping of an ocean wave spectrum into a synthetic aperture radar image spectrum. J. Geophys. Res. 1991, 96, 10713-10729. [CrossRef]

16. Hasselmann, S.; Bruning, C.; Hasselmann, K. An improved algorithm for the retrieval of ocean wave spectra from synthetic aperture radar image spectra. J. Geophys. Res. 1996, 101, 6615-6629. [CrossRef]

17. Collard, F.; Ardhuin, F.; Chapron, B. Extraction of coastal ocean wave fields from SAR images. IEEE J. Ocean. Eng. 2005, 30, 526-533. [CrossRef]

18. Mastenbroek, C.; de Valk, C.F. A semi-parametric algorithm to retrieve ocean wave spectra from synthetic aperture radar. J. Geophys. Res. 2000, 105, 3497-3516. [CrossRef]

19. Schulz-Stellenfleth, J.; Lehner, S.; Hoja, D. A parametric scheme for the retrieval of two-dimensional ocean wave spectra from synthetic aperture radar look cross spectra. J. Geophys. Res. 2005, 110, 297-314. [CrossRef]

20. WAMDIG. The WAM model-A third generation ocean wave prediction model. J. Phys. Oceanogr. 1988, 18, 1775-1810.

21. Hasselmann, K. Measurements of wind-wave growth and swell decay during the Joint North Sea Wave Project (JONSWAP). Erganzung zur Deut. Hydrogr. Z. 1973, 12, 1-95.

22. Johnsen, H.; Engen, G.; Hogda, K.A.; Chapron, B.; Desnos, Y.L. Validation of ENVISAT-ASAR wave mode Level 1 and 2 products using ERS SAR data. IEEE Int. Geosci. Remote Sens. Sym. Pro. 2000, 4, 1498-1500.

23. Lyzenga, D.R. Unconstrained inversion of wave height spectra from SAR images. IEEE Trans. Geosci. Remote Sens. 2002, 40, 261-270. [CrossRef]

24. Schulz-Stellenfleth, J.; Konig, T.; Lehner, S. An empirical approach for the retrieval of integral ocean wave parameters from synthetic aperture radar data. J. Geophys. Res. 2007, 112, 1-14. [CrossRef]

25. Li, X.M.; Lehner, S.; Bruns, T. Ocean wave integral parameter measurements using Envisat ASAR wave mode data. IEEE Trans. Geosci. Remote Sens. 2011, 49, 155-174. [CrossRef]

26. Stopa, J.E.; Ardhuin, F.; Collard, F.; Chapron, B. Estimating wave orbital velocities through the azimuth cut-off from space borne satellites. J. Geophys. Res. 2016, 120, 7616-7634. [CrossRef]

27. Shao, W.Z.; Zhang, Z.; Li, X.F.; Li, H. Ocean wave parameters retrieval from Sentinel-1 SAR imagery. Remote Sens. 2016, 8, 707-721. [CrossRef] 
28. Grieco, G.; Lin, W.; Migliaccio, M.; Nirchio, F.; Portabella, M. Dependency of the Sentinel-1 azimuth wavelength cut-off on significant wave height and wind speed. Int. J. Remote Sens. 2016, 37, 5086-5104. [CrossRef]

29. Stopa, J.E.; Mouche, A. Significant wave heights from Sentinel-1 SAR: validation and applications. J. Geophys. Res. 2017. [CrossRef]

30. Fernandez, D.E.; Carswell, J.R.; Frasier, S.; Chang, P.S.; Black, P.G.; Marks, F.D. Dual-polarized C- and Ku-band ocean backscatter response to hurricane-force winds. J. Geophys. Res. 2006, 111, 275-303. [CrossRef]

31. Hwang, P.A.; Fois, F. Surface roughness and breaking wave properties retrieved from polarimetric microwave radar backscattering. J. Geophys. Res. 2015, 120, 3640-3657. [CrossRef]

32. Romeiser, R.; Graber, H.C.; Caruso, M.J.; Jensen, R.E.; Walker, D.T.; Cox, A.T. A new approach to ocean wave parameter estimates from C-band ScanSAR images. IEEE Trans. Geosci. Remote Sens. 2015, 53, 1320-1345. [CrossRef]

33. Hersbach, H.; Stoffelen, A.; Haan, S.D. An improved C-band scatterometer ocean geophysical model function: CMOD5. J. Geophys. Res. 2007, 112, C03006. [CrossRef]

34. Quilfen, Y.; Bentamy, A.; Elfouhaily, T.; Katsaros, K.; Tournadre, J. Observation of tropical cyclones by high-resolution scatterometry. J. Geophys. Res. 1998, 103, 7767-7786. [CrossRef]

35. Masuko, H.; Okamoto, K.; Shimada, M.; Niwa, S. Measurement of microwave backscattering signatures of the ocean surface using X band and Ka band airborne scatterometers. J. Geophys. Res. 1986, 91, 13065-13083. [CrossRef]

36. Li, X.F. The first Sentinel-1 SAR image of a typhoon. Acta Oceanol. Sin. 2015, 34, 1-2. [CrossRef]

37. Li, X.F.; Zhang, J.A.; Yang, X.F.; Pichel, W.G.; DeMaria, M.; Long, D.; Li, Z.W. Tropical cyclone morphology from spaceborne synthetic aperture radar. Bull. Am. Meteorol. Soc. 2013, 94, 215. [CrossRef]

38. Friedman, K.; Li, X.F. Storm patterns over the ocean with wide swath SAR. Johns Hopkins APL Tech. Dig. 2000, 21, 80-85.

39. Li, X.F.; Pichel, W.G.; He, M.X.; Wu, S.; Friedman, K.; Clemente-Colon, P.; Zhao, C. Observation of hurricane-generated ocean swell refraction at the gulf stream north wall with the RADARSAT-1 synthetic aperture radar. IEEE Trans. Geosci. Remote Sens. 2002, 40, 2131-2142.

40. Hwang, P.; Li, X.F.; Zhang, B. Retrieving hurricane wind speed from dominant wave parameters. IEEE J. Sel. Top. Appl. Earth Obs. Remote Sens. 2017, 1-10. [CrossRef]

41. Zhang, B.; Perrie, W.G. Cross-polarized synthetic aperture radar: A new potential technique for hurricanes. Bull. Am. Meteorol. Soc. 2012, 93, 531-541. [CrossRef] 